\title{
Applied Power Electronic Technology Curriculum Reform----The Cultivation of Practice Ability
}

\author{
Yaling $\mathrm{Jin}^{1}{ }^{1}$, , Yue Yang ${ }^{1}$ and Yinsheng Liu ${ }^{2}$ \\ ${ }^{1}$ Shenyang institute of technologySchool, Fushun 113122, China; \\ ${ }^{2}$ Shenyang Ligong University, Shenyang 110159, China. \\ a37954119@qq.com
}

\begin{abstract}
For automation, electrical engineering, applied colleges by means of power electronic technology in this course curriculum status, and other aspects of social demand and the application prospect of analysis, research, adjust the course content and the replacement of old and new knowledge, combining theory with practice and simulation analysis of the teaching method, and more than 1000 machine test platform instead of traditional test paper for the corresponding reform, thus in such aspects as performance evaluation and competition ability has made some achievements.
\end{abstract}

Keywords: Applied; Power electronic technology; Teaching methods; The teaching reform; Machine test platform

\section{应用型电力电子技术课程改革----实践能力的培}

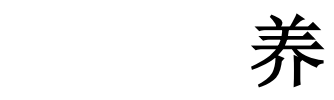

金亚玲 ${ }^{1}$ ，杨玥 ${ }^{1}$ ，刘寅生 ${ }^{2}$

(1. 沈阳工学院信息与控制学院, 辽宁省抚顺市 中国; 2. 沈阳理工大学 自动化与电气工程学院, 辽宁省 沈阳市 中国）

摘要: 针对应用型院校自动化、电气工程等专业, 通过对电力电子技术这门课程在课程地位、社会需求和应用前景等方 面进行分析、研究, 在课程内容进行相应的调整和新旧知识的替换、用实践加仿真结合理论分析的教学方法以及 1000 余题 的机考平台代替传统的试卷等方面进行相应的改革，从而在成绩考核及大赛能力等方面都取得了一定的成绩。

关键词: 应用型; 电力电子技术; 教学方法; 教学改革; 机考平台

引言

电力电子技术是一门利用电力半导体开关器件对电能进行高效率的变换和控制的技术，它是 20 世纪 后半世纪发展起来的一门崭新的技术, 如今已发展成为一门横跨电子、电力和控制三个领域的新型的工程 技术学科，是以应用为主的综合性工程技术基础类课程。

\section{1 基于工程实践的应用型电力电子技术课程改革与实施的具体意义}

\section{1 课程地位}

电力电子技术是我校电气工程及其自动化、自动化专业重要的专业基础课，主干课。学生只有在很好 的掌握了电力变换和控制的基础上, 才能对输出的电源进行按照所需进行控制, 并为电机拖动控制系统、 变频技术和电力系统装置等课程打下基础。

\section{2 社会需求}

从近几年的社会用人的需求情况来看, 用人单位大多要求学生具备电机控制（变频调速）的能力（本 
能力的重点就是电力电子技术)。因此电力电子技术是自动化、电气工程及其自动化专业的重要的专业基 础课, 在以实践为主要目的应用型人才培养过程中起到了非常重要的作用。所以进行电力电子技术的教学 改革, 势在必行。

\section{3 基于工程实践的应用型电力电子技术课程改革与实施应用前景}

目前, 几乎所有的工科学校均有自动化专业, 大部分学校已有电气工程及其自动化或正在申请该专业, 而所有的自动化与电气工程及其自动化均开设了电力电子技术课程, 其中所讲的内容为电力变换的占到 $80 \%$, 所以基于工程实践的应用型电力电子技术课程改革与实施如果能够改革成功, 本课题的研究内容不 仅对本门课程，对该专业其他同类课程同样具有显著的借鉴和推广价值，可见是有广大的推广空间的。

\section{2 改革内容}

为了贯彻我校 “应用为本、学以至用” 的办学理念, 在教学过程中要求学生做到 “会用、会看、会做”。 会用即要求学生能够正确使用电力电子器件, 重点是参数选择、保护、驱动及使用中的特殊问题。会看即 要求学生熟练掌握变流电路的分析方法, 不仅掌握定性分析, 而且掌握定量计算，同时要掌握实验方法。 会做即要求学生能够正确设计简单的变流电路。在教学过程中我们做到理论教学授予学生基本理论和分析 方法; 实践教学贯穿于整个课程体系，以巩固深化理论知识和培养学生实践动手能力为目的。

\section{1 课程内容的改革}

本部分主要是授课内容的取舍，与以往不同，不再大面积、罗列式讲解，而是有针对性，与时俱进性 的讲解目前广泛应用的内容, 如表 1 中的逆变电路部分, 目前应用交流电机使用超过了直流电机, 所以逆 变电路变得更为重要, 增加了该部分的课时。而开关电源的使用也被广泛普及, 并且大赛也经常有相关内 容，所以增加了该部分的授课内容，具体内容如表 1 所示。

\section{2 授课方法的改革}

为了实现理实一体化, 从实际应用引出课题, 引出学生兴趣然后进行适当的理论分析, 加入虚拟实验 平台（multisim 进行系统仿真）配合实验室实验设备加强对理论内容的理解，同时学会实践应用，具体方 法如图 1 所示。

\section{表 1 课程内容的改革}

\begin{tabular}{cll}
\hline 章节 & 以往授课内容及重点 (学时分配) & 改革后授课内容及重点 (学时分配) \\
\hline & 不可控(电力二极管)、半控 (晶闸 & \\
& 管)、全控器件 (GTO、GTR、 \\
& MOSFET、IGBT) 的组成结构、 & 不可控(电力二极管)、半控 (晶闸 \\
管)、全控器件 (GTO、GTR、 & 工作原理、特性分析、主要参数、 & MOSFET、IGBT) 的使用 \\
& 主要类型、器件的驱动电路分析、 & (4 学时理论+4 学时实验) \\
& 器件的保护电路分析等 （8 学 & \\
& & \\
& 时理论+2 学时实验) & \\
\hline
\end{tabular}




\begin{tabular}{|c|c|c|}
\hline \multirow{7}{*}{ 整流电路 } & 单相半波整流电路（晶闸管） & \\
\hline & 单相桥式全控整流电路 (晶闸管) & 单相桥式全控整流电路（IGBT） \\
\hline & 单相全波整流电路（晶闸管） & 单相全波整流电路（IGBT） \\
\hline & 单相桥式半控整流电路 (晶闸管) & 三相半波可控控整流电路（IGBT） \\
\hline & 三相半波可控控整流电路（晶闸 & 三相桥式全控整流电路（IGBT） \\
\hline & 管） 三相桥式全控整流电路（晶 & (16 学时理论+6 学时实验) \\
\hline & 闸管) (24 学时理论+4 学时实验) & \\
\hline \multirow{4}{*}{ 逆变电路 } & 有源逆变电路 & 有源逆变电路 \\
\hline & 电压型逆变电路 & 电压型逆变电路 \\
\hline & 电流型逆变电路 & 电流型逆变电路 \\
\hline & (4 学时理论+2 学时实验) & ( 8 学时理论+2 学时实验) \\
\hline \multirow{3}{*}{$\begin{array}{l}\text { 斩波电路 } \\
\text { (大赛内容) }\end{array}$} & 降压斩波电路 & 降压斩波电路 \\
\hline & 升压斩波电路 & 升压斩波电路 \\
\hline & (4 学时理论) & (4 学时理论) \\
\hline \multirow{3}{*}{ 交流变换电路 } & 交流电力控制调压电路 & 交流电力控制调压电路 \\
\hline & 调功电路 & 调功电路 \\
\hline & (4 学时理论+2 学时实验) & (4 学时理论+2 学时实验) \\
\hline \multirow{3}{*}{$\begin{array}{l}\text { 开关电源 } \\
\text { (大赛内容） }\end{array}$} & & 不间断电源 \\
\hline & & 开关电源 \\
\hline & & (4 学时理论) \\
\hline
\end{tabular}

4.2.1降压斩波电路

降压斩波电路

(Buck Chopper)

- 电路结构

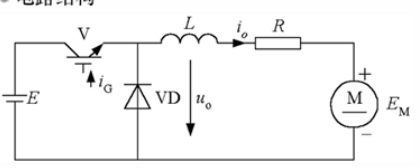

○讲解、分析、现场软件仿真相结合

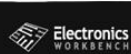

matriais o Specil

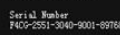

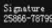

multisım 8

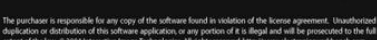

and
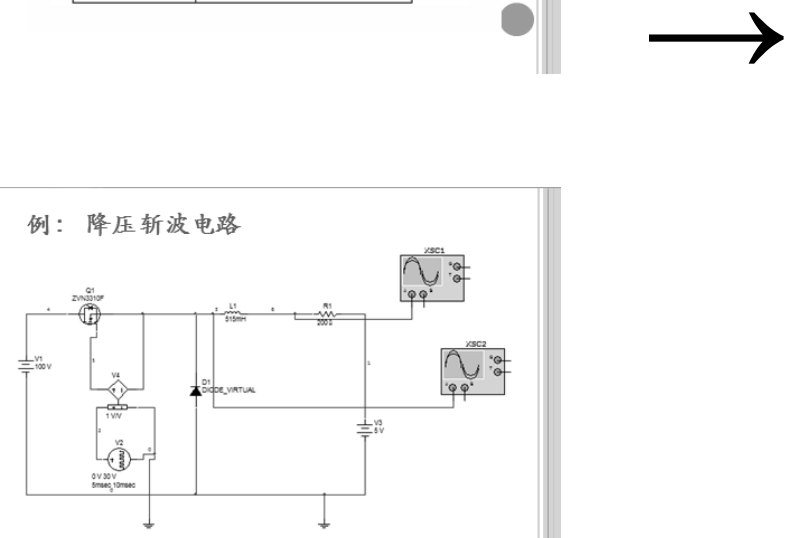

降压斩波电路，电感值较大

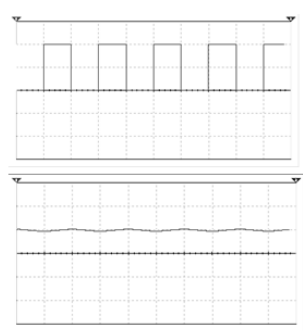




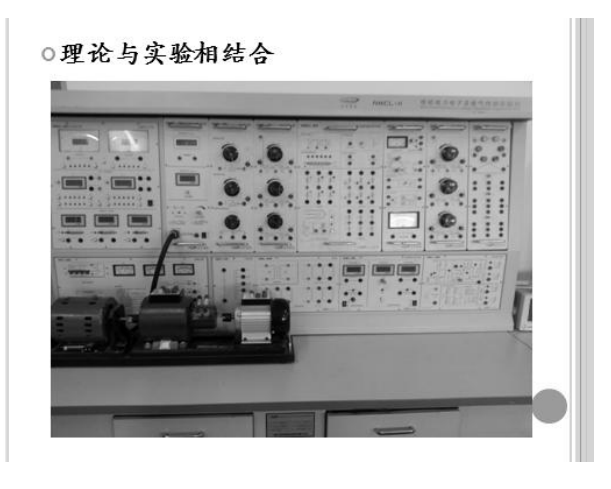

图 1 授课方法的改革

\section{3 考核方式的改革}

采用理论与实践相结合的考核方式, 理论的考核也不再是传统的计算分析, 而变成机考平台, 基础知 识, 应用能力的考核。具体如图 2 所示。

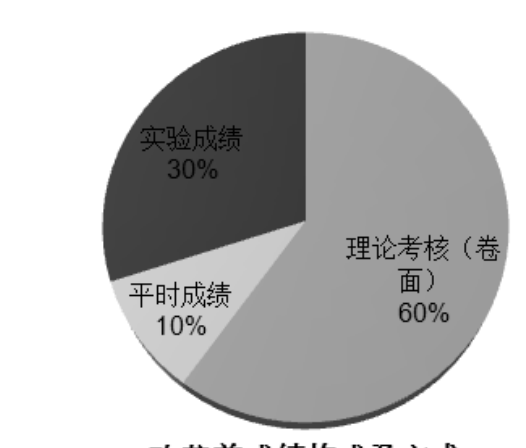

改革前成绩构成及方式

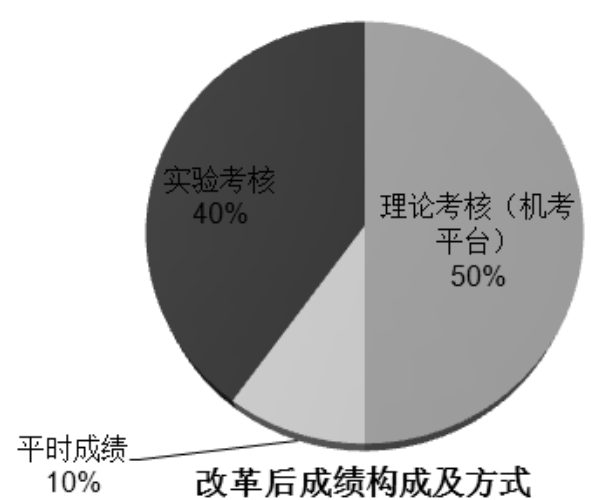

图 2 考核方式及比例的改革

\section{4 配套资源平台的建设与改革}

修改对应大纲, 学习有所依据 $\longrightarrow$ 编写适应我们学习的教材 $\longrightarrow$ 课件以动画为主, 增加趣味性 $\longrightarrow$ 题 库建设。

\section{3 本项目的特色与创新}

\section{1 与时俱进, 紧密联系实际}

根据电力电子技术的发展, 在授课内容上给予整合, 电路的分析设计上尽量使用现在广泛使用的大功 率、高频率的典型全控器件 IGBT 代替传统的半控器件晶闸管。

\section{2 应用理解大于控制设计}

针对我们学校学生的特点, 注重培养 “应用型” 人才, 对知识的掌握更侧重于各种电路的作用、特点 及与各个电路对应的输出结果; 而不是如何设计该电路。所以理论考核方式采用机考平台, 更注重客观性 知识的掌握。

\section{3 与电子大赛紧密结合, 充分调动学生学习积极性}

历年来大学生电子设计竞赛中都会有一道关于电源类的题目, 而所采用的基础知识就是本门课程斩波 与逆变的内容, 所以无论是在绪论引入还是在具体内容的课程引入时, 都选用大赛内容, 学生学习兴趣会 更加浓厚。也为大赛打下基础。 


\section{4 改革成效}

经过两年多探索，工程型教学模式改革已收益显著。这首先表现在通过试点，一线教师的教育理论水 平和教改能力获得明显提升, 先后发表了若干篇高水平论文, 并培养了开展教育教学实验的主动性与积极 性, 提高了学生培养质量。一方面, 学生的考试成绩非常理想, 平均成绩达到了 80 分以上。另一方面一 些学生先后在高水平科技竞赛活动中获奖, 例如大学生电子设计大赛分别有一、二、三等奖的好成绩。

\section{5 致谢}

感谢 JG201520 基金。

\section{参考文献:}

[1] 荣军, 万军华，陈曦等. 计算机仿真技术在电力电子技术课堂教学难点中的应用 $[J]$. 实验技术与管理, 2012 , 8 (期) : 103-105.

[2] 张明. 现代电力电子集成技术综述 $[J]$. 大功率变流技术，2016，2(期) :1-7

[3] 张红娟, 路秀芬, 孟海涛. “电力电子技术” 课程工程实践的教学改革 $[J]$. 电气电子教学学报, 2016, 6 (期) : 127-129.

[4] 孙晓明. “电力电子与电机调速技术应用” 课程教学改革与探索 $[J]$. 教育与教学研究, 2016, 1(期)：93-96.

[5] 牛天林, 樊波, 张强等. Matlab/Simulink 仿真在电力电子技术教学中应用 [J]. 实验室研究与探索, 2015 , 2 (期) : 84-87.

[6] 刘少克, 龙志强, 陈贵荣. “电力电子技术” 课程的案例式教学 $[J]$. 电气电子教学学报, 2014，6 (期)：56-58.

[7] 杜红艳. 浅论电力电子技术在新能源领域的应用 $[J]$. 河南科技, 2014，5(期)：51-53.

[8] 王兆安, 刘进军. 电力电子技术 $[\mathrm{M}]$. 第五版. 北京:机械工业出版社, 2011.

[9］牛百齐，常淑英. 电工技术基础与仿真（Multisim 10）［M]．第一版. 北京：电子工业出版社，2015.

[10］鲍敏. 电力电子技术项目教程 $[M]$. 第一版. 北京: 机械工业出版社, 2015 .

\section{References:}

[1] Rong june, Wan Junhua, Chen Xi, etc. Difficult Point Application in Power Electronic Technology Teaching of Computer Simulation Technology [J].Experimental Technology and Management, 2012 (Volume 8):103-105.

[2] Zhang Ming. Summary of Integrated Technology of Modern Power Electronics [J].High Power Converter Technology,2016 (Volume 2):1-7

[3] Zhang Hongjuan, Lu Xiufen, Meng Haitao. teaching reform of course Engineering practice of "Power Electronics Technology" [J].Journal of Electrical and Electronic Education,2016 (Volume 6):127-129.

[4] Sun Xiaoming. Course Teaching Reform and Exploration of "Technology Applications of Power Electronics and Motor Drive" [J].Education and Teaching Research,2016 (Volume 1):93-96.

[5] Niu Tianlin, Fan Bo, Zhang Qiang, and so on.Matlab/Simulink Simulation application in Power Electronic Technology Teaching [J].Research and Exploration in Laboratory,2015 (Volume 2):84-87.

[6] Liu Shaoke, Long Zhiqiang, Chen Guirong. case study of Course "Power Electronics Technology" [J].Journal of Electrical and Electronic Education,2014 (Volume 6):56-58. 
[7] Du Hongyan. Discussion on Application of Power Electronic Technology in New Energy Field [J].Henan Science and Technology, 2014 (Volume 5):51-53.

[8] Wang Zhao'an, Liu Jinjun. Power Electronics Technology [M].The Fifth Edition. Beijing: China Machine Press, 2011.

[9] Niu Baiqi, Chang Shuying. Fundamentals of Electrical Technology and Simulation (Multisim10) [M].The first edition. Beijing: Publishing House of Electronics Industry, 2015.

[10] Bao Min.Project Course of Power Electronics Technology [M].The first edition. Beijing: China Machine Press, 2015. 